\title{
acabado de un firme de hormigón
}

SANDRO ROCCl, ingeniero de caminos

Supongamos que el hormigón fresco acaba de sufrir la última pasada de la máquina extendedora, vibradora. Lo principal está hecho ya; pero quedan una serie de pequeñas y algo enojosas, pero importantísimas, operaciones de acabado, que son las que marcan la diferencia entre el éxito y el fracaso más o menos encubierto de todas las costosas operacio, que son las que marcan la diferencia entre el exito y el fracaso mas o menos encubierto de todas las costosas operalo largo de su historia ha venido quedando claro que el firme de hormigón es una obra que requiere buen sentido al proyectar y una ejecución esmerada; sólo estos dos factores, especialmente el segundo, pueden garantizar el éxito de la construcción.

Para empezar, voy a mencionar una operación puerilmente sencilla, pero que resulta muy conveniente con vistas a futuras investigaciones sobre estos temas, siempre sujetos al sancionamiento de la práctica. Se trata de establecer en cada losa una referencia que permite identificarla. Esta referencia suele ser, en forma de un número de orden establecido por el constructor, y la fecha de hormigonado. El número permite hacer referencia a un "parte de obra", en que se llevan anotadas las características del hormigón empleado, tipo y número de pasadas de la maquinaria utilizada, y en fin, todos los entes, según el buen sentido del encargado de la obra. Este marcaje se efectúa sobre el hormigón fresco por medio de unos troqueles que se hunden en él (por ejemplo, un centímetro), dejando su huella al retirarse, como se hace con los sellos de lacre; se suele situar en las esquinas de la losa. No merece esta ope-
ración más mención.

Generalmente, después de la última pasada de la maquinaria, ya sea de la máquina vibradora, ya sea el cuchillo vibrante para hacer juntas, se suele proceder inmediatamente a la operación de barrido. Pero hay ocasiones en que dicho barrido-del que voy a tratar luego-debe aplazarse unas horas por las razones que sean; por ejemplo, por ir retrasado el cuchillo de las juntas (aunque éste no es el caso normal). Queda entonces el hormigón fresco en una situación

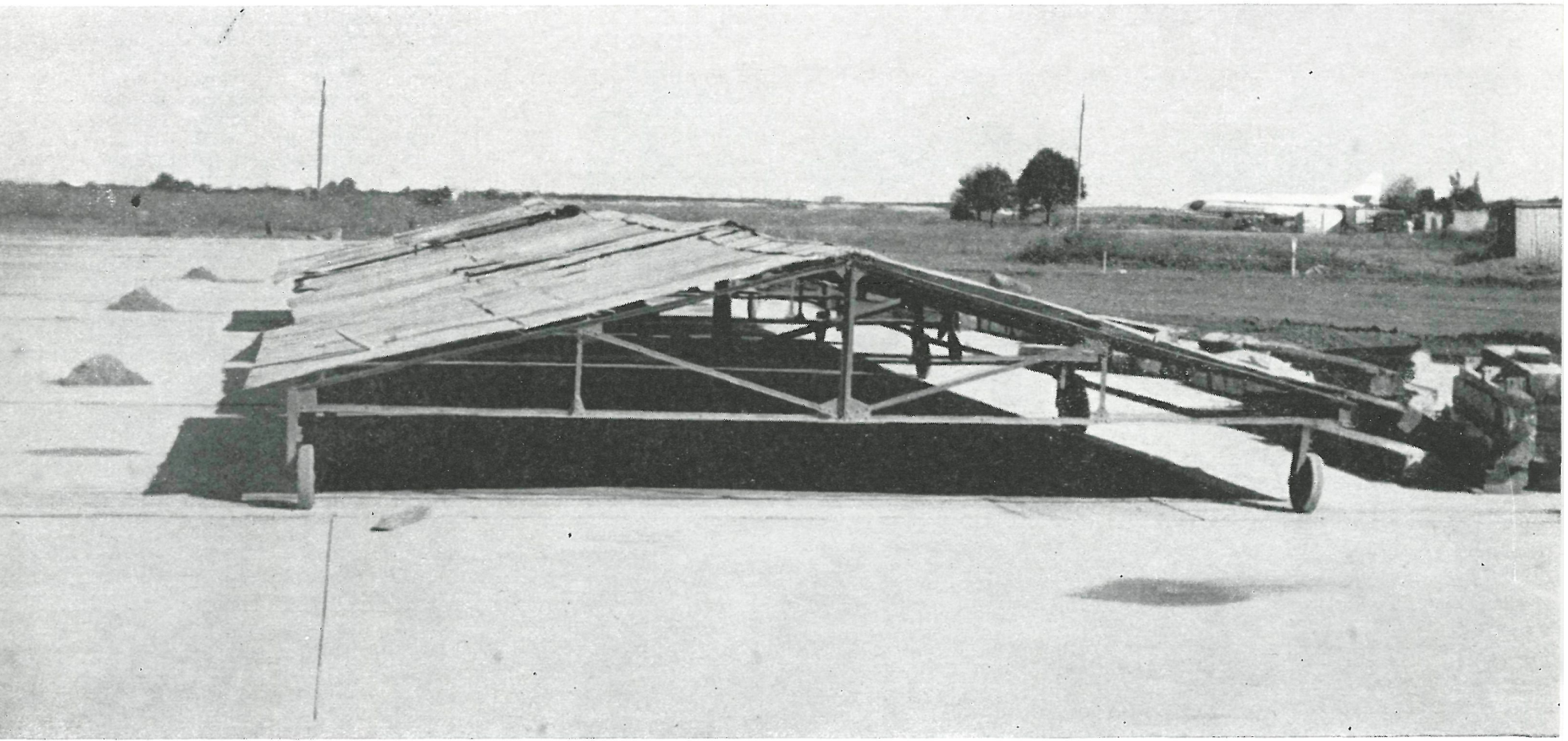

muy peligrosa, pues la evaporación puede hacerle perder suficiente agua como para aumentar fuertemente la retracción de fraguado, que, al verse coartada por el rozamiento del terreno, puede iniciar la fisuración de la losa; máxime ofreciendo el hormigón fresco muy escasa o casi nula resistencia a la tracción. Por otro lado, en estos momentos iniciales en que al acabar de pasar la máquina vibradora queda en superficie la lechada refluída en la operación de vibrado, resulta imposible recurrir a productos de curado del tipo que forman una película impermeable en la superficie; pues estos productos se diluirían en la lechada y no "prenderían". En estos casos se ha revelado eficaz el empleo de techumbres productos se diluirían en la lechada y no "prenderían". En estos casos se ha revelado eficaz el empleo de
móviles, que ruedan sobre los encofrados (fig. 1) a veces arrastradas por la misma máquina vibradora. 

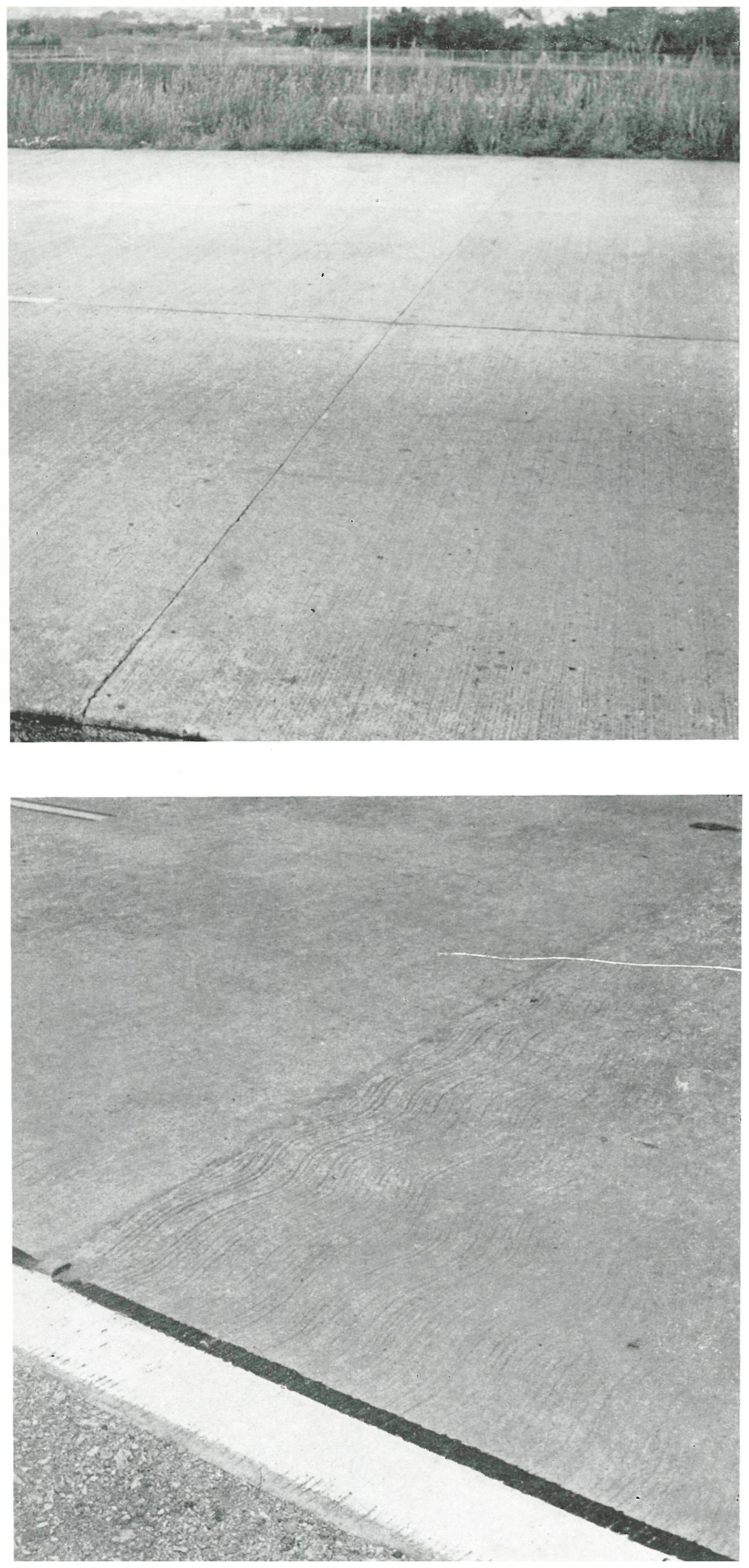

Estas techumbres rodantes defienden al hormigón contra la evaporación superficial, manteniendo inmediato a su superficie un ambiente saturado chumeun ambiente saturado de humedad. Para ello suelen ser muy bajas, impermeables y con vertiente a dos aguas (no olvidemos que tampoco es conveniente que llueva encima del hormigón fresco). Otro enemigo es el viento, que no sólo puede levantar las techumbres (aunque se hacen adecuadamente pesadas a este objeto), sino que, canalizado entre la techumbre y el firme, puede activar la evaporación. Para evitar esto, se disponen paredes evitar esto, se disponen paredes de lona que cuelgan, tanto a los lados como en los extremos del tren de techumbre, impidiendo la circulación del aire. Una última un material claro (generalmente fibrocemento, aunque se ha llegaclo a utilizar el aluminio) para gado a utillzar el aluminio) para evitar la accion ava los rayos del sol.

Pero, generalmente, el barrido sigue inmediatamente a la última operación mecanizada. La operación, como su mismo nombre indica, consiste en pasar desde una pasarela, transversalmente al eje del camino, una escoba de púas metálicas por la superficie del hormigón po superimiendo unas estrías esco imprimiendo unas estrias en la zona superficial, rica en mortero. La escoba suele pasar en trayectoria rectilínea (fig. 2), aunque en ocasiones, como en la pista experimental de Fontenay-Trésigny, se puede apoyar su mango sobre un perfil sinuosidal de contrachapado, obteniéndose un hermoso estriado sinuosida un her (fig. 3), que parece ser mejora también el coeficiente de desli-
zamiento transversal.

Como el objeto de estriado, sea éste recto o de otra forma cualquiera, es el aumento de la rugosidad y, por tanto, del coeficiente de rozamiento por rodadura sobre el firme, resulta muy interesante, a este respecto, la experimentación llevada a cabo en Bélgica sobre las ventajas del barrido.

El objeto de estos ensayos ha sido determinar tres cosas principalmente:

PRIMERA.-La influencia del estriado sobre el coeficiente de rozamiento del firme.

SEGUNDA.-La evolución del estriado con el desgaste, y su regeneración eventual.

TERCERA.-La influencia de la dosificación en finos del hormigón sobre el coeficiente de rozamiento. 
Las probetas empleadas se obtuvieron por corte de losas fabricadas en el Laboratorio del Centro de Información de 1a Industria Cementera Belga, en las que se variaba la dosificación en finos del hormigón, y su estriado superficial; a veces fuerte $\mathrm{y}$ grueso, a veces fino y tupido. Su comportamiento antideslizante fue comparado al de probetas extraídas de losas lisas obtenidas en obra.

Se utilizaron dos procedimientos de medidas del coeficiente de rozamiento: Uno de ellos fue el péndulo de Leroux (fig. 4), cuyo principio, idéntico al del péndulo de Charpy, utilizado en los ensayos de resiliencia, mide la pérdida de energía del péndulo por el rozamiento de un patín de caucho, del tipo de neumático, contra el firme. Un dispositivo basculante asegura el contacto durante un recorrido de unos $10 \mathrm{~cm}$. Una lectura 100 significaría un amortiguamiento total de la energía debido al rozamiento. Una lectura 0 indicaría un amortiguamiento nulo. El otro procedimiento de medida permite una reproducción esquemática de un frenazo (fig. 5). La fuerza horizontal engendrada por el rozamiento se transmite a un muelle, cuya deformación se amplifica y registra adecuadamente. Conociendo también la reacción vertical del conjunto, se deduce inmediatamente el coeficiente de rozamiento.

Ambos métodos de medida en Laboratorio (quiero llamar la atención sobre el hecho de que estos procedimientos se aplican a probetas de tamaño reducido $\mathrm{y}$ no a firmes en escala natural) dan resultados comparables; $\mathrm{y}$ mayor exactitud el segundo.

Hay que distinguir ahora entre rozamientos en seco o sobre firme mojado. Fl primero, a igualdad de materiales, tanto en el neumático como en el flrme, depende de la superficie de contacto efectiva entre dicho neumático y el firme. Los ensayos belgas han demostrado una notable correlación entre el coeficiente de rozamiento en seco y la superficie media de contacto, deducida mediante la interposición de un papel carbón entre la rueda y el firme (fig. 6).

Según esto, interesaría reducir al mínimo la importancia de las estrías practicadas en el firme: una losa lisa sería lo ideal en seco, obteniéndose valores en el rugosímetro Leroux del orden de 80 a 85 .

Pero el firme necesita conservar, al menos en gran parte, sus cualidades antideslizantes cuando se haya mojado. El agua forma una película sobre la superficie de firme que actúa de lubricante, favoreciendo el deslizamiento. Esto hace que sea necesario romper esa película de agua por medio de asperezas que deben revestir la forma de "crestas" mejor que de "valles" a través de los cuales la tensión superficial pueda seguir tendiendo la película líquida. De aquí nace la necesidad de estriar el firme por medio de numerosos surcos paralelos.

Esta necesidad, combinada con la máxima superficle de contacto, hace que se hayan mostrado más adherentes las losas con estrías numerosas y finas, mejor que las que tienen estrías profundas más distanciadas.

Pero es que además es evidente que las aristas vivas de las estrías están sujetas a un desgaste debido a la rodadura y a los frenazos del tráfico. En los ensayos belgas antedichos, las probetas se colocaron en una máquina rotatoria (figura 7), que primero las sometió a medio millón de pasadas de una rueda de caucho que producía una presión de unos $3 \mathrm{~kg} / \mathrm{cm}^{2}$, equivalente a la del tráfico estimado. Después se procedió a 25.000 ciclos de frenado en seco con interposición de un patín de caucho, con la misma presión. Se tomaron medidas del coeficiente de rozamiento en seco y sobre mojado con la frecuencia necesaria, y por los dos procedimientos distintos. Los ensayos demostraron interesantes conclusiones.

PRIMERA.-El coeficiente de rozamiento en seco se mantuvo prácticamente constante (entre 80 y 84 por 100 del rugosímetro Leroux), tanto durante los ciclos de rodadura, como durante los de frenado: tanto en las losas lisas, como en las estriadas.

SEGUNDA-E1 coeficiente de rozamiento sobre el firme mojado muestra primero una franca disminución en las losas estriadas (de 74 a 70 Leroux) durante los 4.000 primeros ciclos de rodadura (fig 8). Esto corresponde a la destrucción de las aristas más vivas de las estrías formadas por la lechada superficial. Seguidamente $\mathrm{y}$ hasta los 5.000 ciclos de
rodadura en que se realizó el ensayo, se mantiene constante alrededor de 60; aumentando ligeramente (5 por 100 Leroux) durante los ciclos de frenado. Esto es debido a que las estrías supervivientes están formadas por mortero rico, que presenta una elevada resistencia. Las losas lisas siguien una evolución paralela, 10 por 100 Leroux más abajo.

\section{rugosímetro Leroux}

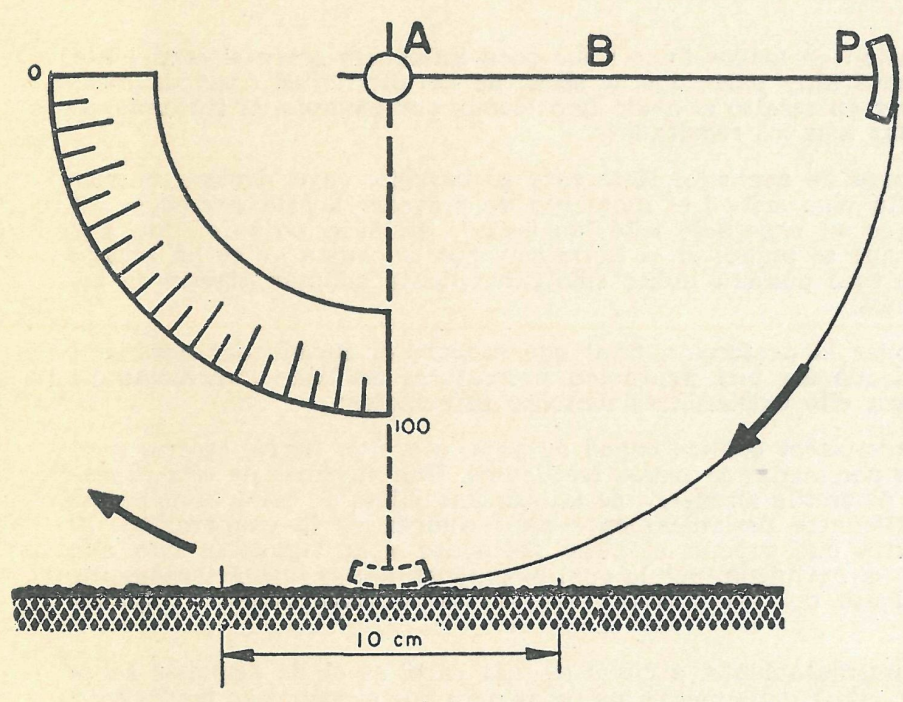

Esquema del aparato.

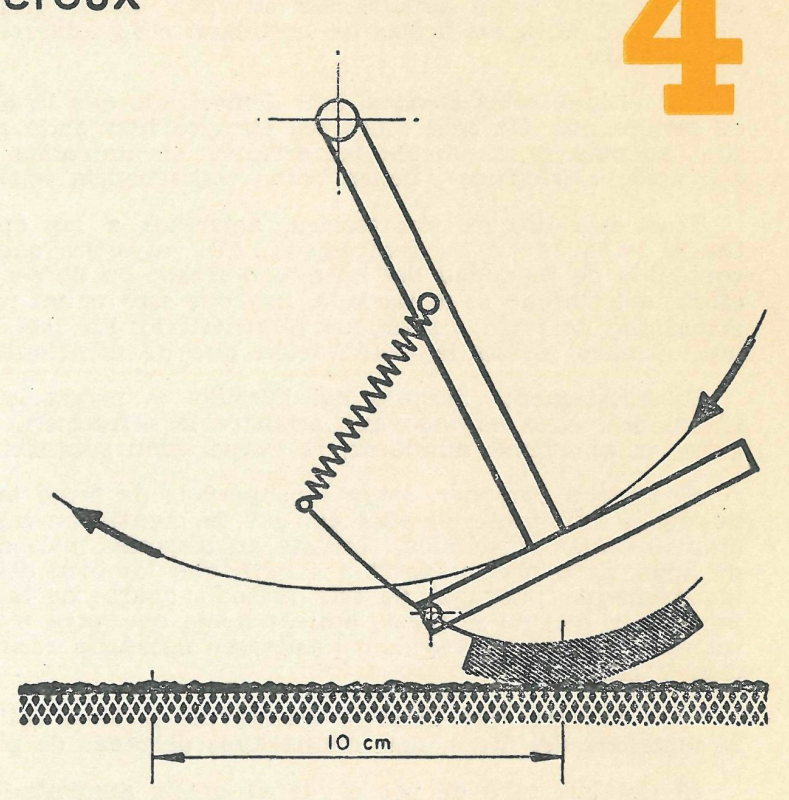

Dispositivo que mantiene el patín en contacto con la superficle. 


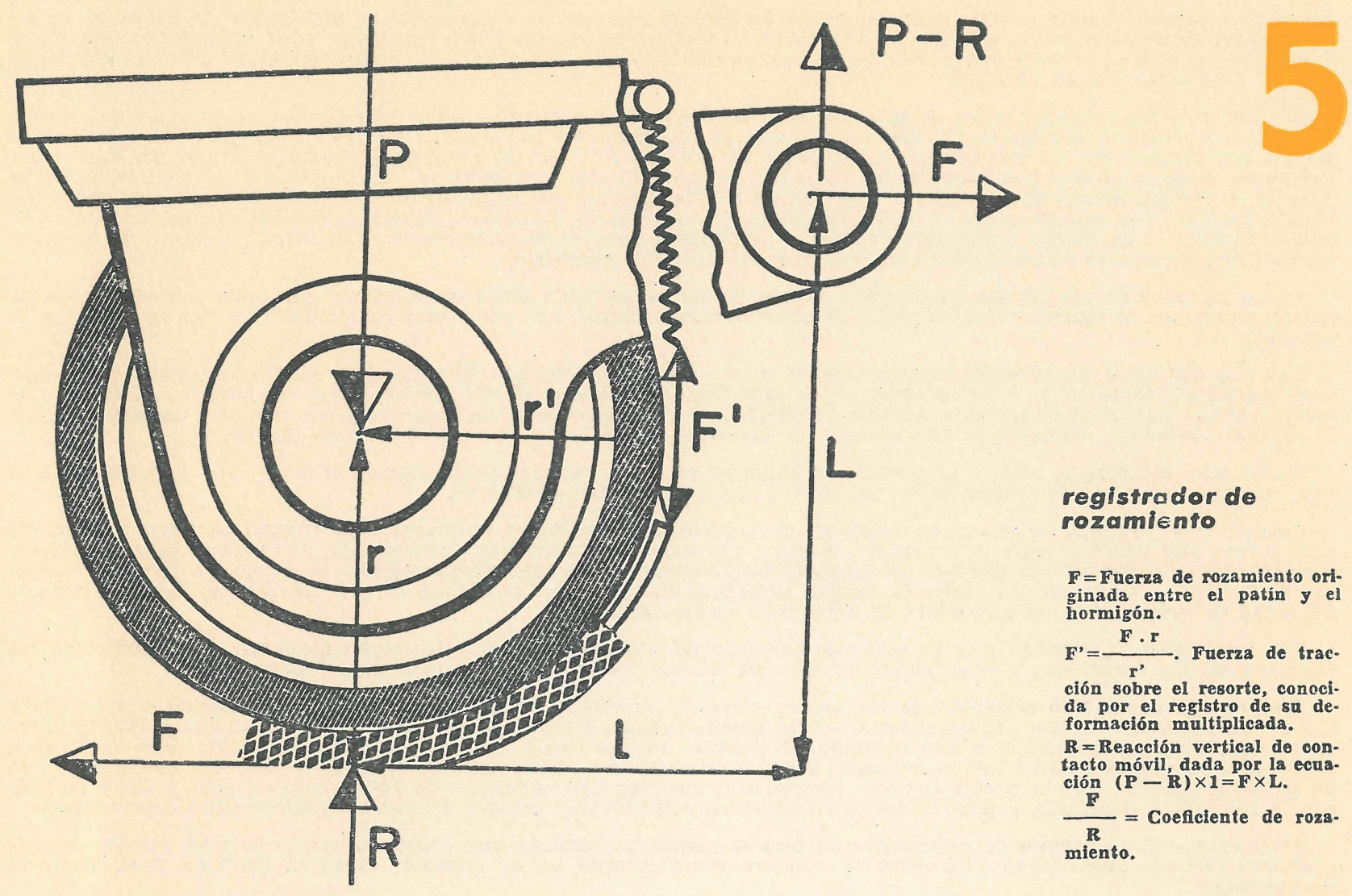

Vemos, por lo tanto, que el desgaste debido al tráflco apenas modifica el coeficiente de rugosidad en seco, y estabiliza muy rápidamente el coeficiente de rugosidad sobre mojado en el $70 \%$ del correspondiente al firme seco.

Pero los ensayos han llegado más lejos aún. Sustituyendo el patín de goma por una muela de carborundo se llegaron a borrar completamente las estrías de la superficie de las probetas, provocando una caída brusca de los coeflcientes de rozamiento. Pues bien: un tratamiento superficial con ácido clorhídrico diluído al $50 \%$ durante unos diez minutos (hasta que cese la efervescencia) seguido de un cuidadoso lavado con a cia hace resaltar de nuevo los áridos nutos (hasta que cese la efervescencia), seguido de un cuidadoso lavado con agua, hace resaltar de nuevo los aridos finos del hormigón, disminuyendo algo la superficie de contacto efectiva (el coeficiente de rozamiento en seco queda
en $80 \%$ Leroux en vez de 84), pero restableciendo la rotura de la película líquida, por lo que se devuelve al coeficiente de rozamiento sobre mojado casi su valor inicial (hasta $70 \%$ Leroux). He aquí un método barato y eficaz, pues, de rejuvenecer antiguos firmes de hormigón cuya adherencia, siempre buena, se haya visto un poco atacada por el paso de los años.

Por último, estos ensayos han demostrado que la dosificación en áridos finos tiene poca influencia sobre el coeficiente de rozamiento. No sólo todos los ensayos han dado resultados muy parecidos, a pesar de las diferentes dosificaciones: sino, además, precisamente las acciones encaminadas a poner en resalto el árido fino (como, por ejemplo, el tratamiento con ácido clorhídrico), tienen como consecuencia igualar más aún los resultados.

Tras esta disquísición teórica, volvamos a las operaciones de acabado. Referente al barrido, cuya enorme importancia ha quedado ya demostrada sólo advertiré que resulta algo crítico el momento de proceder a esta operación. El contenido de humedad del hormigón fresco ha de ser tal, que su superficie esté "luciente". Si la lechada refluída por contenido de humedad del hormigón fresco ha de ser tal, que su superficie esté "luciente". Sí la lechada refluída por efecto del vibrado es demasiada, hay que esperar un poco a que se seque; si el hormigón, por el contrario, se ha secado precauciones contra la evaporación que he mencionado antes.

Inmediatamente después del barrido, es necesario disponer la protección final que asegure el curado del hormigón en un ambiente húmedo que aminore la retracción, impidiendo aś́ una fisuración prematura. Se hace imprescindible evitar o, al menos, aminorar, la evaporación superficial: para ello existen tres métodos principales:

Se pueden disponer, sobre la superficie de firme terminado, sacos o unas capas de paja, o arena, tierra, escoria granulada u otro material análogo que se mantienen húmedos por medio de riegos frecuentes. Una variante de este procedimiento, más económica, consiste en disponer unos diques de arcilla alrededor de la losa con objeto de crear unas balsas dimiento, más economica, consiste en disponer unos diques de arcilla alrédedor de la losa con objeto de crear unas bén inconveniente principal de este método, aparte de la molestia que supone el riego frecuente y la vigilancia que ello inconveniente principal de este método, aparte de la molestia que supone el riego frecuente y la vigilancia que ello intensa durante el fraguado puede ser necesario recurrir al uso de techumbres móviles con la consiguiente complicación y gasto.

Otro sistema, que tiene la ventaja de poderse aplicar inmediatamente, aunque es más caro, es el de disponer sobre la superficie del firme unas membranas delgadas de plástico, convenientemente lastradas para que el viento no laș levante.

El sistema, caro de por sí, ve su precio aumentado por los frecuentes desgarres en las membranas, inevitables en toda obra, que hacen que duren muy poco. Han de cuidarse además los recubrimientos, con objeto de evitar pérdidas de agua por los bordes. Fil procedimiento se usa tan sólo en países de economía muy saneada... 


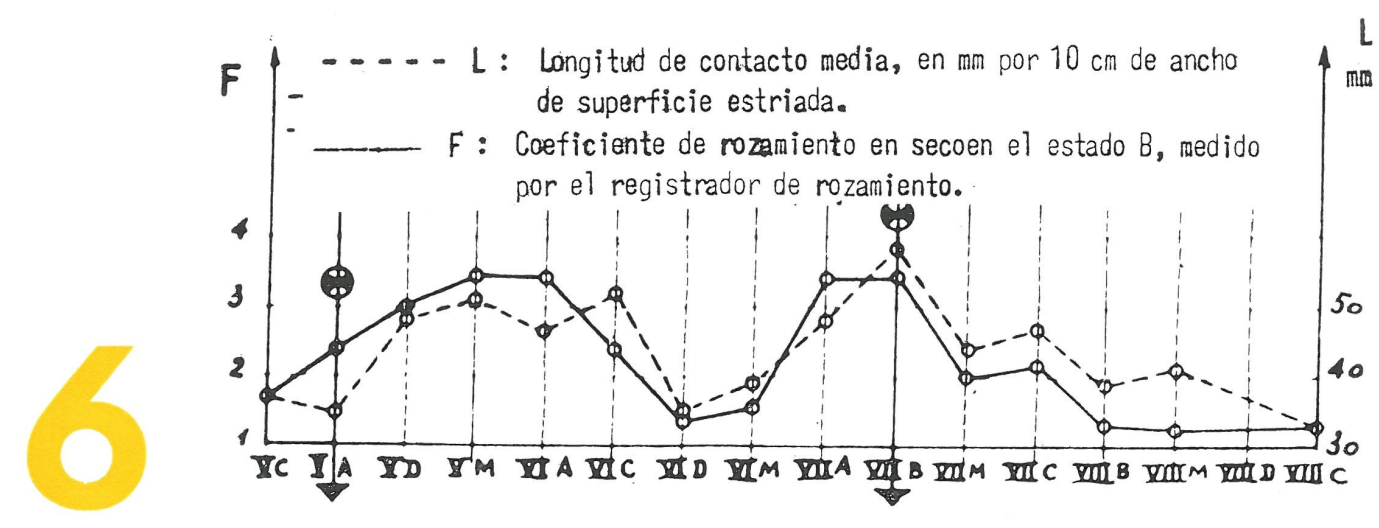

目寻

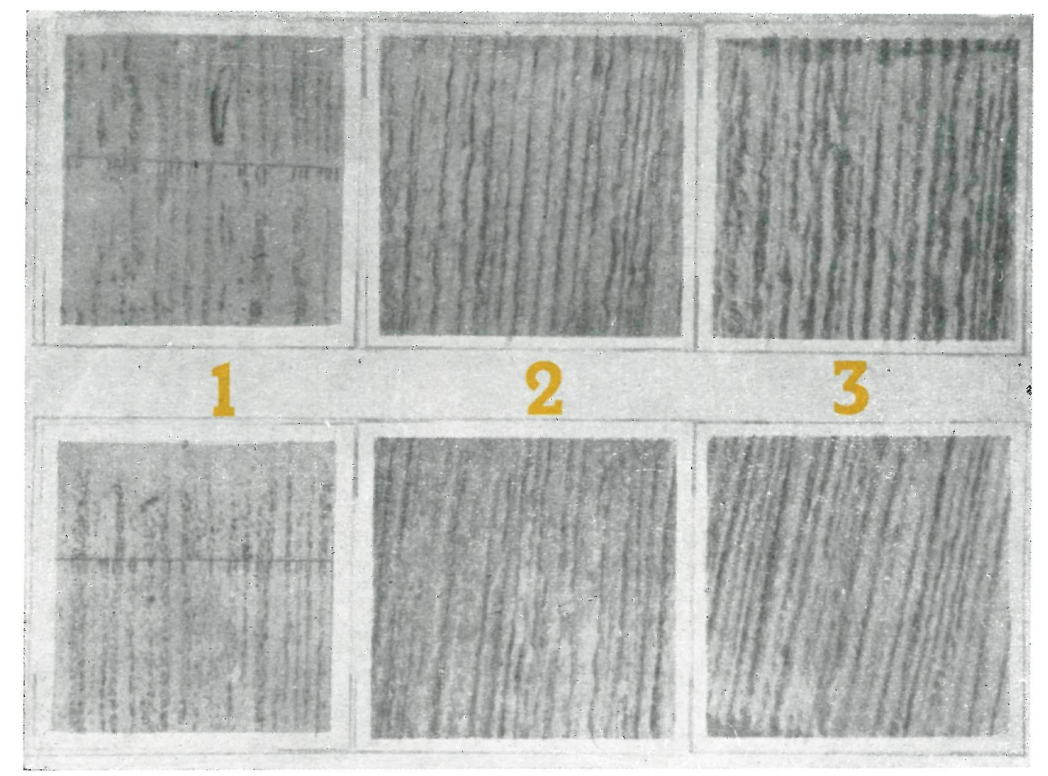

\section{influencia \\ de la superficie de confacto:}

\section{Estado A}

20.000 pasadas de rodadura

\section{Estado B}

500.000 pasadas de rodadura más 25.000 pasadas de rozamiento

3 Huella en papel carbón - Estado B

Variación del estado de la superficie, en función del desgaste

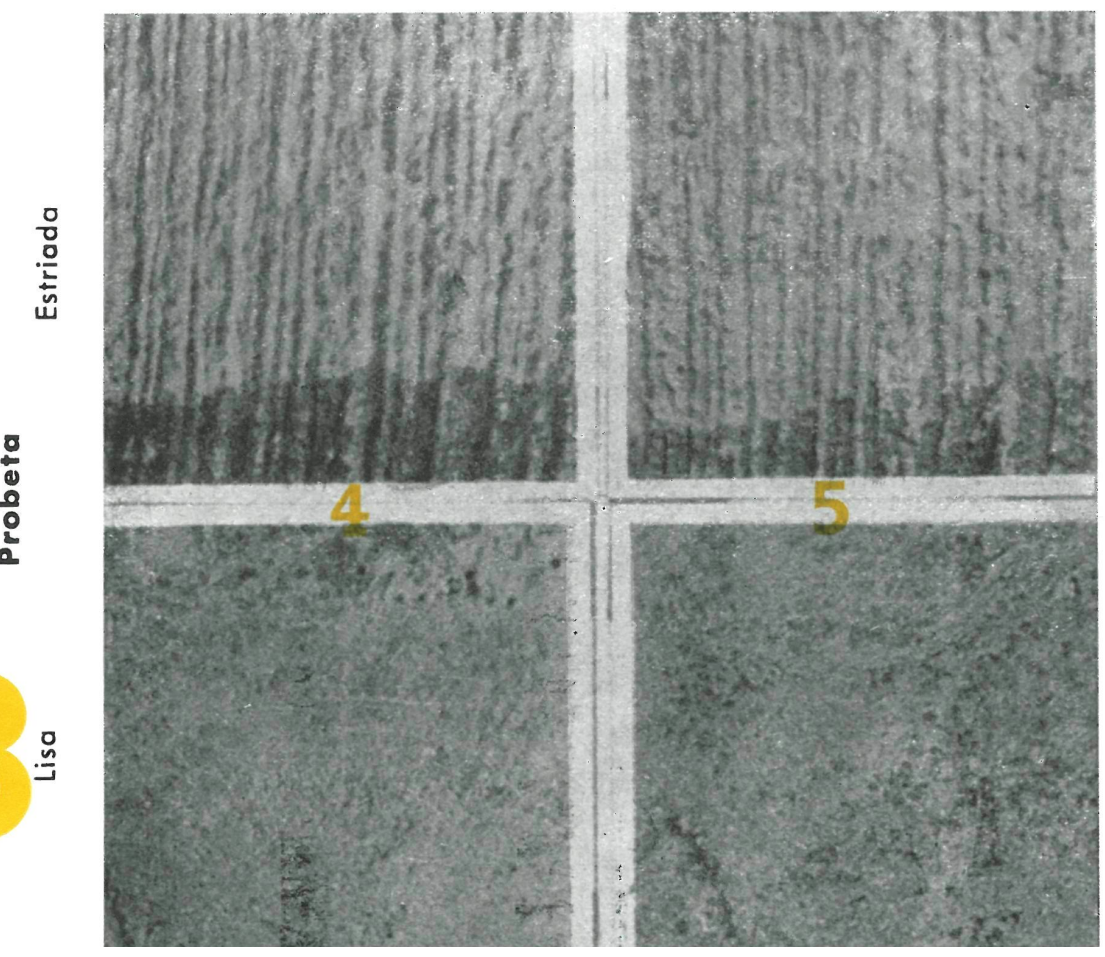

Desgaste por rueda número de pasadas:

420.000 rodaduras

550.000 rodaduras más 25.000 rozamiento
Fotos: SANDRO ROCCI

Centre d'Information de l'Industrie Cimentière Belge 

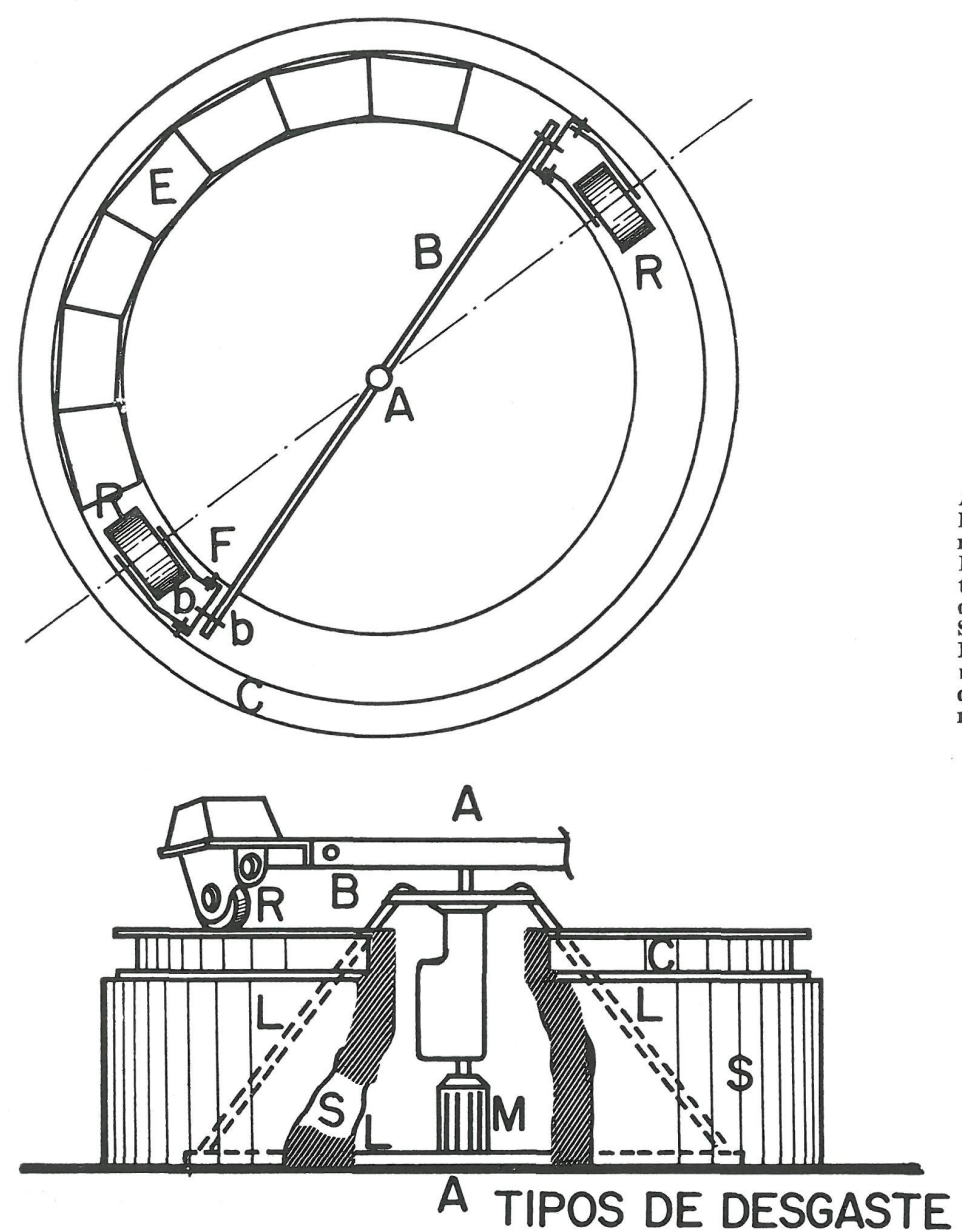

A, Eje vertical de rotaciôn. B, Brazo horizontal.-C, Corona metálica. $-\mathbf{R}$, Ruedas.F, Horquilla.-M, Motor elécdad.-L, Armazón metálico. $\mathbf{S}$, Base de hormigón. - E, Probeta.-b - b', Eje que permite la rotación de la horquilla y su colocación en varias posiciones.

\begin{tabular}{|c|c|c|}
\hline \multirow{2}{*}{$\begin{array}{c}\text { DESGASTE POR } \\
\text { RODADURA }\end{array}$} & \multicolumn{3}{|c|}{ DESGASTE POR ROZAMIENTO } \\
\cline { 2 - 3 } & PATIN DE CAUCHO & PATIN DE CARBORUNDO \\
\hline RUEDA LIBRE & RUEDAS FRENADAS \\
\hline
\end{tabular}

Cabe, por último, adherir la membrana directamente a la superficie del hormigón. Esto se hace pulverizando desde poca altura un producto a base de resinas emulsionadas, que "rompen" casi inmediatamente, formando una película impermeable sobre la superficie misma del hormigón. Tales productos se conocen en el mercado con el nombre de productos de curado o "curing compounds", y existen diferentes tipos y marcas. Siempre que se utilicen productos de eficacia reconocida, ésta es con mucho la mejor solución, pues se puede aplicar inmediatamente. Para defender la frágil película impermeable del tráfico de obra, se puede recubrir al día siguiente con paja o tierra húmeda, que además aisla térmicamente al firme fresco, lo cual es siempre conveniente.

La protección debe mantenerse de una a dos semanas, según el clima más o menos húmedo de la localidad. Los plazos de apertura al tráfico que preconizan diversos países europeos oscilan entre diez y veinte días.

El plazo de desencofrado de firme es generalmente lo menor posible, debido a que el encofrado, siempre muy caro, debe ser reutilizado inmediatamente para reducir el número de elementos necesarios.

Esta misma consideración hace que la operación de desencofrado deba realizarse con mucho cuidado, para evitar que se dañen los elementos; y que, de vez en cuando, se debe proceder a una reparación o conservación de los mismos.

Aunque en otro lugar me he ocupado extensamente de juntas, quiero advertir aquí que, como la operación de sellado se realiza una vez retirada la protección contra la evaporación superficial, es necesario proteger las juntas abiertas contra la penetración de cuerpos duros, por ejemplo piedras, o arena, que pudiern encajarse en ellas, provocando su mal funcionamiento posterior. Por lo tanto, es necesario taparlas, generalmente con papel o cinta adhesiva, o incluso (lo cual constituye una solución mejor) con chapas de unos 25 a $30 \mathrm{~cm}$ de ancho, que protegen eficazmente a la junta contra dicha penetración de cuerpos duros. 